looked for once every fourth or sixth year, tor it is not claimed that inoculation cures " sickness" and increases the frequency with which leguminous crops can be grown. Even a 50 per cent. increase in crop, useful though it would be, would in these circumstances hardly effect any particular revolution in agricultural practice. We are therefore unable to follow the author when he remarks:- "For a few thousand pounds the 2I million acres of poor barren land in this country could be made productive and rendered capable of finding work for and supporting such a population that both the food problem and the unemployed problem would be easy of solution.... Waste land réclaimed and made fertile for $6 d$. an acre !. . ." It would have been better if the author had induced an agricultural friend to revise this estimate. We are told on pp. 8 and to that inoculation will be a failure when the soil is too acid and in need of lime, when it is deficient in phosphates and potash, when the physical conditions of the soil are unfavourable, or when drainage is needed. Barren land in England commonly suffers from several or all of these defects. How far would sixpence an acre go in putting them right?

At a time when the farmer needs, and is willing to accept, all the assistance the scientific investigator can give him, the fact that an enthusiastic worker like Prof. Bottomley has directed his attention to agricultural botany is a matter for congratulation, and we can only regret that in this, his first appeal to the practical man, his enthusiasm should have outrun his judgment. However, although we must regard the present production as unsatisfactory, we still look forward to sound work from the author on this subject, and we wish him success in his work on the numerous and difficult problems connected with soil inoculation.

E. J. R.

\section{MATHEMATICAL EDUCATION AND RESEARCH.}

THE annual meeting of the Mathematical Association was held at King's College, London, on Saturday, January 25. The proceedings bear abundant testimony to the great changes which are taking place in the methods of teaching mathematics, and show that these changes are not confined to the subject of elementary geometry. Mr. W. J. Dobbs showed what useful work could be done by means of simple home-made apparatus in the teaching of mechanics, his apparatus consisting merely of spiral springs with cardboard scales attached for illustrating applications of the parallelogram law, and suspended sticks for illustrating the principle of the lever and the balance. $\mathrm{He}$ further showed how the solution of problems on accelerated motion could be greatly simplified by the application of direct methods not involving such restrictions as to units as are necessary in working with "poundals" or "slugs." Mr. C. O. Tuckey made a distinct step in advance in his suggestions as to the methods of introducing the properties of convergent series to students who require these series principally in the study of the calculus, and it is interesting to compare his views with those which prevailed twenty or thirty years ago, when the calculus was regarded as something sacred which should not be handled by students until they had passed through a lengthy period of probation in working with algebraic series. Mr. F. J. W. Whipple's lantern-slides, showing how the convergency of certain trigonometric series could be illustrated by diagrams drawn by mere beginners, were a revelation to those who had approached the subject by the study of pages of long formulæ. Mr. W. E. Bryan suggested a very original way of introducing similar figures in geometry, a method which, however, may well form a basis of further discussion and criticism. An apparatus for drawing rectangular hyperbolas was shown by $\mathrm{Mr}$. H. L. Trachtenberg.

In his presidential address Prof. G. H. Bryan, F.R.S., dealt with the uses of mathematics and the training of mathematical teachers. It was necessary that the public should be made aware of the important part which higher mathematical research had played, and was destined to play, in practical applications on which the prosperity of a nation depended. As an instance, Prof. Bryan referred to the seemingly unpractical and uninteresting study of the properties of imaginary quantities, without which modern applications of electricity to purposes of commerce, including wireless telegraphy, could never have reached their present developments. In order to overcome the existing lack of public interest in mathematical matters it was important that the university training of every mathematical teacher should afford him some insight into the research aspect of some one branch of the subject, and the experiments that had already been made in this direction in the university colleges of Wales showed that this ideal was quite capable of attainment. Turning to the teaching of mathematics in elementary schools, Prof. Bryan expressed the opinion that the children of the working man should learn to measure and calculate correctly in order that they might become more efficient and improve their positions in the labour market. If their teaching was conducted in such a way as merely to stimulate in them a spirit of luxury and discontent as distinct from a desire for self-improvement, the working classes had quite as much cause for complaint as the tax-payers. But in the training of elementary teachers, antiquated and unpractical methods are still prevalent, and are often greatly encouraged by examinational requirements.

\section{RADIOGRAPHY IN PEARL FISHING.}

THE products of the sea are commonly wasted to a very deplorable degree by those who gather and use them. In no instance is this waste more marked than in the search for pearls. By the old method, which is still in vogue as a general rule, an enormous number of the so-called oysters are taken from their habitat and destroyed without any thought of economy. It is said that only one pearl is found in 100 oysters, and only I per cent. of the pearls found are of any commercial value. Thus some 10,000 of the precious molluscs are sacrificed for every useful pearl obtained. Among these victims there must be a vast amount of immature pearls or seed, pearls in posse, which might grow and become valuable gems, which are deprived of that possibility by premature destruction.

In the year I9oI Prof. Raphaël Dubois took radiographs of pearls in situ within the shell of Unio prolifera, and obtained a clear view of their size and situation in spite of the thickness of the shell in which they were encased. $\mathrm{He}$ showed these radiographs at the Linnean Society of Lyons, and remarked that the X-rays might receive a novel application if used in the fisheries of Ceylon, and the destruction of a vast number of the prized molluscs might thus be avoided.

The difficulty of applying the $\mathrm{X}$-rays to many thousands of shells per diem seemed sufficient to deter the ordinary person from such a laborious attempt. However, a few years later an electrical engineer of New York, Mr. John J. Solomon, who took an interest in the question of pearls, was struck by the same idea of using the X-rays to detect the existence of pearls within the shell of the living animal. He was then unaware of the earlier experiments of Prof. Dubois, but promptly set himself about the work from a commercial point of view.

$\mathrm{He}$ found that an exposure necessary to obtain a good picture did not in any way injure the animal, and even an exposure of ten times as long could be applied without causing its death from the effect of the rays. The dangers lay rather in the removal of the bivalve from its normal attachment and in the time required for its transit from its bed to the laboratory of the photographer: for the pearl oyster is really a kind of mussel, which holds on to some fixed object by a brush of fibrils (byssus) growing from its body

Thus the fundamental principle of Prof. Dubois, to save the life of unremunerative bivalves, bids fair to be carried out by American ingenuity and capital.

For practical purposes, where many thousands of shells have to be radiographed daily, a completely novel kind of plant had to be devised. This was done, and final success was considered to be well in view, when roo clear radiographs could be taken on an average every fifteen seconds.

NO. 1997, VOL. 77] 
Mr. Solomon often succeeded in taking as many as 500 per minute. In this process some hundred shells are exposed at a time to the rays. The oysters, spread on trays, are carried under the specially constructed cylinders by means of an electric motor. These great cylinders are cooled by means of suitable water jackets, and can thus be kept working continuously.

The oysters in which there is no sign of pearl formation are put back to their beds. Those in which goodsized pearls are detected are removed and opened, and the pearls promptly utilised. Those showing no pearls of adequate commercial value, but containing promising seed or immature pearls, are carefully placed in hospital. This hospital has rather a novel object; not the cure of the pearl disease (for the much prized gem is but a pathological growth), but, on the contrary, everything is done to keep the mollusc in stutu quo ante so that the disease may progress as rapidly as possible to the production of valuable pearls and to the death of the incurable patient.

The question seems to arise, can the normal, or perhaps we should say the abnormal, conditions of the pearlproducing bivalve be well enough imitated in captivity to ensure the continued growth of the pearls? May not the "change of water" (as they must be kept nearer the surface) secure for the sufferers immunity from their diseased process? One might have imagined that a greater amount of sunlight, more oxygen, altered temperature, different nutrition, lessened pressure, and other changed conditions we think not of, would so influence the life of the molluse that it might depart from its pathological but useful habit of producing these valued round bits of shell material, and the hospital might thus prove a true Kur-Anstalt instead of a pearl-breeding depôt. But Mr. Solomon tested these points, and he has satisfied himself that, if he can be certain to transmit in all circumstances the oysters to and from his laboratory without injury to their well-being, all other difficulties have already been overcome. As to the lucrative commercial value of the undertaking, time alone can tell; sufficient has not yet elapsed to make it demonstrable by actual proof that pearls can thus be hatched en gros.

\section{UNIVERSITY AND EDUCATIONAL}

$$
\text { INTELLIGENCE. }
$$

Cambridge.-Two Graces will be offered to the Senate at the Congregation on Thursday, February 13 ; the first gratefully accepts the generous offer of the Drapers' Company to contribute a sum of $200 l$. a year until rigra towards the stipend of a second professorship in the department of agriculture, and the second establishes in the University a professorship of agricultural botany.

The council of the Senate has reported that it is of opinion that the University should hold a Darwin celebration in the course of the year 1909. The council points out that Charles Darwin was born on February 12, 1809, and that the "Origin of Species" was published on November 24, 1859 . The hundredth anniversary of the former event, and the fiftieth anniversary of the latter, will therefore fall in the course of the year 1909. It is suggested that representatives of universities and other learned bodies, together with distinguished individuals, should receive invitations to visit the University on the should Should this report be confirmed by the Senate, the counci will appoint a committee to consider the details of the proposed celebration. The week beginning June 20, 1909, appears to the council to be the most suitable time for the celebration.

LONDON,--The degree of D.Sc. has been conferred on Mr. H. B. Fantham for a thesis entitled "Spirochaeta (Trypanosoma) balbianii (Certes) and Spirochaeta anodontae (Keysselitz); their Movements, Structure, and Affinities," and other researches in zoology.

Dr. Otto Stapf has commenced a university course of ten lectures on "Grasses: their Structure, Biology, Distribution, and Classification," and Dr. Beddard, F.R.S., a course of four lectures on "The Circulatory System of Reptiles." Both courses are being delivered at University College on Mondays, the botany lectures at 4 p.m. and the zoology lectures at 5 p.m., admission to these lectures being free.

$$
\text { No. I997, voL. 77] }
$$

A university course of four advanced lectures in zoology on "Tooth Development and Morphology" will be given by Prof. H. W. Marett Tims, at Bedford College for Women, at 5 p.m. on Tuesdays, commencing March 3 . Admission will be free.

Arrangements have been made for university courses in geology by Prof. Garwood, on "The Geology and Physiography of Arctic Europe" (in March); by Prof. Seeley, F.R.S., on "The Thames and its Tributaries" (in May); by Dr. Evans, on "Recent Advances in the Determination of Minerals by Optical Methods" (in June); and by Miss Raisin, on "The Geological Structure of the Area of the Vosges", (in October).

In future, a candidate for the D.Sc. degree may be required by the examiners, as an additional test, to submit within a given period a reasoned report on a subject prescribed by them. Candidates for the B.Sc. honours degree in mathematics as internal students are to be allowed, under certain conditions, to submit research work, and such work will be taken into account in estimating their qualifications.

The Lord Alverstone, G.C.M.G., Lord Chief Justice of England, will present prizes and certificates to students of evening classes and the day college of the South-Western Polytechnic, Chelsea, on March i3.

THE Board of Education has issued a return (325) showing the application by local authorities of funds for higher education in England and Wales during the official year 1905-6. It appears that the total expenditure on account of education other than elementary during the year was $3,355,434 l$. Of this amount, $706,149 l$. was spent on secondary schools and $234,182 l$. on pupil-teacher centres. On behalf of evening schools and institutions for higher and technical education, $1,200,789 l$. was expended, and in day schools of similar scope $258,5 \mathrm{r} 7 \mathrm{l}$. Exhibitions and bursaries at secondary schools, pupil-teacher centres, evening and day technical institutions, accounted for $376,762 l$. The training of teachers cost $7 \mathrm{r}, 9 \mathrm{rol}$., the salaries of officers other than teachers $120,53 \times l$, and $150,660 l$. was paid on account of loans. The part of the total amount which was expended in Wales rcached $214,185 l$, more than half of which was devoted to secondary schools.

\section{SOCIETIES AND ACADEMIES. \\ LONDON.}

Royal Society, November 21, 1907. - "Note on the Sensibility of the Ear to the Direction of Explosive Sounds." By A. Mallock, F.R.S.

Soon after the introduction of modern rifles, which give their projectiles a velocity much higher than that of sound, the author noticed that when standing in a position in front of the gun, and not far from the line of fire, the sound seemed to come, not from the firing point, but from some point considerably in advance of the gun. The natural explanation seemed to be that the sound thus heard was not that of the explosion itself, but was caused by the wave-surface, which is generated in the air by the projectile moving at a velocity higher than that of sound. In 1808 the author made observations at the ranges at Broundown to see if the apparent directions agreed with this supposition; and in the present year he has again made similar experiments in much more favourable circumstances. It is clear (if the source of the sound is due to the wave caused by the projectile) that the apparent direction of the sound will be the normal to the wave-surface, and that if the direction of this normal is known, the velocity of the projectile, at the time that that particular portion of the wave-surface was generated which ultimately reaches the observer, can be calculated.

These observations are now recorded, not as giving a practical method of ascertaining the velocity of projectiles, but as showing that the ear can distinguish with considerable accuracy the direction of a sound which consists, not of a train of waves, but, at most, of two waves only. The figure gives the plan of the range and the stations at which the observations were made.

The arrows through these points show the direction of the sound as judged by ear. Each arrow is the mean 